\title{
Intra-aortic balloon pumping: seven years' experience
}

\author{
WT VIGNESWARAN, IJ REECE, KG DAVIDSON
}

From the Royal Infurmary, Mearnskirk Hospital, and Western Infirmary, Glasgow

ABSTRACT The indications for intra-aortic balloon pumping vary widely from country to country and from one cardiac surgical unit to another. Its use in Glasgow from 1976 to 1983 in 63 patients has been reviewed. Six of the patients $(9.5 \%)$ had the intra-aortic balloon inserted before cardiac surgery, $43(68.2 \%)$ at the time of surgery, and $14(22.2 \%)$ in the postoperative period. Of the 63 patients, 11 could not be weaned from cardiopulmonary bypass despite intraaortic balloon pumping, and died in the operating room. A further 35 patients had intra-aortic balloon pumping but died in the immediate postoperative period. Seventeen patients $(27 \%)$ survived from six weeks to 3.3 years after receiving the support of intra-aortic balloon pumping. There was major morbidity in 11 patients $(17 \%)$, all of whom developed degrees of ischaemia due to ileofemoral arterial obstruction in the leg in which the balloon was inserted. The conservative use of the method in this centre is reflected in the high mortality of these patients.

Intra-aortic balloon counterpulsation is a temporary method of assisting cardiac output by producing inflation and deflation of an elongated balloon in the thoracic aorta. Precise timing produces sequential inflation of the balloon with gas $(30-40 \mathrm{ml}$ of helium or carbon dioxide) during diastole and active deflation of the balloon during systole. This raises mean aortic diastolic pressure and lowers the peak aortic systolic pressure. Reduction of systolic pressure lowers the resistance to left ventricular ejection, reducing left ventricular afterload and myocardial consumption. In addition, raising the mean diastolic pressure increases blood flow to the coronary arteries. ${ }^{1}$ This affects the diastolic pressure time index/tension time index or endocardial viability ratio $^{1}$ in a beneficial way and forms the physiological basis for the clinical application of balloon pumping.

Intra-aortic balloon pumping is used most effectively as an adjunct for weaning patients with left ventricular dysfunction from cardiopulmonary bypass and in the treatment of a low cardiac output state and refractory hypotension after cardiac surgery. ${ }^{1-5}$

There has been widespread use of intra-aortic balloon pumping as a method of temporarily improving the cardiac condition before surgery. The two main

\footnotetext{
Address for reprint requests: Mr KG Davidson, FRCS, Department of Cardiothoracic Surgery, Royal Infirmary, Glasgow G31 2ER.

Accepted 19 April 1985
}

groups are: (1) Patients who have sustained an acute myocardial infarction producing a mechanical complication resulting in low cardiac output. The two conditions commonly seen are (a) papillary muscle rupture resulting in acute mitral regurgitation and $(b)$ ventricular septal defect with a large left to right shunt. ${ }^{1-6}$ (2) Patients with unstable angina, in whom increased coronary blood flow may be sufficient to stabilise a patient with ischaemic myocardium. ${ }^{15-8}$ In recent years, particularly in the United States, intra-aortic balloon pumping has been used electively in high risk patients undergoing cardiac surgery. Balloon pumping is commenced before induction of anaesthesia and continued into the immediate postoperative period. ${ }^{5910}$ Although the early use of balloon pumping has been advocated, the trend in Glasgow cardiac units has remained conservative, early operation being preferred.

This paper reviews our experiences and assesses the influence of balloon pumping on mortality and morbidity when applied in a conservative way.

\section{Patients and method}

From January 1976 to April 19834098 adults underwent cardiac surgery in Glasgow. During this period 63 patients ( 42 of them men) required intra-aortic balloon pumping. Ages ranged from 25 to 72 with a mean of 53 years (men 49 and women 55). Fifteen patients underwent emergency operation within a few hours of admission and 17 had 858 
urgent operations within a few days of admission. Thirty one patients undergoing elective cardiac operation required intra-aortic balloon pumping. The Datascope System 80 or 82 was used in all patients, usually with a double balloon catheter.

\section{Results}

Table 1 shows the clinical diagnoses for patients having intra-aortic balloon pumping and table 2 the pattern of usage of this technique in Glasgow.

\section{PREOPERATIVE INTRA-AORTIC BALLOON PUMPING}

Six patients underwent preoperative intra-aortic balloon pumping; five had cardiogenic shock due to acute myocardial infarction with mechanical complications, four septal rupture, and one mitral regurgitation. The sixth patient, who had left main stem coronary disease, underwent intra-aortic balloon pumping when he developed intractable angina several hours before operation could be undertaken. One patient had balloon pumping for 120 hours before operation but died in the operating room. The remaining patients had intra-aortic balloon pumping before operation for an average of 6.6 hours and after operation for $\mathbf{4 4 . 6}$ hours. Only two of the six were weaned successfully from balloon support and one survived to be discharged from hospital.

\section{INTRAOPERATIVE INTRA-AORTIC BALLOON PUMPING}

Forty three patients had intra-aortic balloon pumping instituted in the operating room-39 for difficulty in weaning them off cardiopulmonary bypass and four for uncontrollable arrhythmia. It was used for an average of 19.3 hours. Eleven of the

Table 1 Surgical procedures carried out in the different disease groups

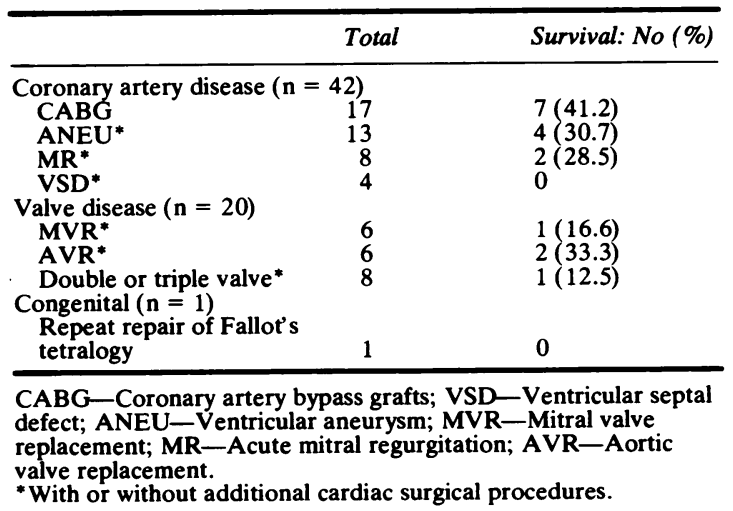

43 patients $(25 \%)$ could not be weaned from bypass despite the use of all available measures, including balloon pumping. Of the 32 patients who were weaned from bypass, 24 ( $56 \%$ of the group of the 43 having intraoperative intra-aortic balloon pumping) were weaned from balloon support and 14 (32.5\%) were long term survivors.

\section{POSTOPERATIVE INTRA-AORTIC BALLOON PUMPING}

Fourteen patients underwent intra-aortic balloon pumping in the early period after cardiac surgery11 for low cardiac output and three for uncontrollable ventricular arrhythmia. Balloon pumping was used for an average of 45 hours. Ten patients (71\%) were weaned from balloon support but there were only two $(14 \%)$ long term survivors.

There were 13 survivors (31\%) among those with coronary artery disease and four $(20 \%)$ among those with valve disease. This difference is not statistically significant.

None of the four patients with postinfarction ventricular septal rupture showed any appreciable haemodynamic improvement with balloon counterpulsation and none survived despite surgical repair.

\section{COMPLICATIONS}

The complications that occurred in this series are summarised in table 3 . The major problem was

Table 2 Trend in the use of intra-aortic balloon pumping (IABP)

\begin{tabular}{llllll}
\hline Year & CPB & IABP & $\begin{array}{l}\text { No not } \\
\text { weaned } \\
\text { off }\end{array}$ & $\begin{array}{l}\text { Survival } \\
(\%)\end{array}$ \\
\cline { 2 - 6 } & No & $\begin{array}{l}\text { Annual } \\
\text { mortality } \\
(\%)\end{array}$ & & & \\
\hline 1976 & 296 & $(8.4)$ & $6(2.02)$ & 2 & 16.6 \\
1977 & 407 & $(9.8)$ & $7(1.71)$ & 2 & 14.2 \\
1978 & 451 & $(6.6)$ & $7(1.55)$ & 0 & 42.8 \\
1979 & 442 & $(4.9)$ & $2(0.45)$ & 0 & 50.0 \\
1980 & 638 & $(6.1)$ & $7(1.09)$ & 1 & 57.1 \\
1981 & 707 & $(6.6)$ & $10(1.41)$ & 4 & 10.0 \\
1982 & 827 & $(6.0)$ & $19(2.29)$ & 2 & 26.3 \\
1983 & 330 & $(4.7)$ & $5(1.51)$ & 0 & 20.0 \\
(to 31 Apr) & 330 & & & & \\
\hline
\end{tabular}

$\mathrm{CPB}-$ Cardiopulmonary bypass operations.

Table 3 Complications associated with intra-aortic balloon pumping

\begin{tabular}{lrr}
\hline & No & $\%$ \\
\hline Ischaemia of the leg & 11 & 17 \\
$\quad$ Died & 8 & \\
Observed & 2 & \\
Fasciotomy & 1 & \\
Embolectomy & 3 & \\
Amputation & 1 & 1.6 \\
Wound infection & 1 & 6.3 \\
Chronic serous discharge & 4 & 3.2 \\
Failure to insert & 2 & \\
\hline
\end{tabular}


ischaemia of the leg due to the combination of relative obstruction of diseased ileofemoral arterial segments by the balloon catheter and low cardiac output. This occurred in 11 patients $(17.5 \%)$, three of whom survived. There was no direct relationship between the duration of intra-aortic balloon pumping and leg ischaemia. In the three survivors the balloon was removed as soon as possible and clot evacuated from the affected artery with embolectomy catheters. In one patient restoration of an adequate circulation to the foot could not be achieved and amputation was eventually required. There was one serious infection in the groin wound and four cases of chronic serous discharge. There was no evidence of embolisation to other organs, aortic dissection, or spinal cord ischaemia.

\section{FOLLOW UP}

The hospital survivors were followed up for six weeks to three years and three months. There were two known deaths, one at 10 weeks (unknown cause) and the other at 11 months (due to cardiac failure). Eleven patients were alive at six months, and six for more than two years.

\section{Discussion}

There has been widespread interest in left ventricular assistance devices over the past decade. These have included the implantable artificial heart, long term support with membrane oxygenators ard partial bypass, intra-aortic balloon counterpussation, and "piggyback" transplantation.' Of these methods intra-aortic balloon pumping is the most widely available and easiest to apply and its value as a left ventricular assist device has been well established. ${ }^{511}$ The proportion of patients surviving intra-aortic balloon pumping depends essentially on the selection criteria applied, and these vary from centre to centre. It has been our policy to offer early or immediate surgery for patients with unstable angina who cannot be controlled with maximal medical treatment, and intra-aortic balloon pumping is reserved for patients with acute left ventricular dysfunction during or after cardiac operation. Nevertheless, 17 of the 63 patients who underwent balloon pumping $(27 \%)$ were long term survivors.

Besides variation in indications for the use of balloon counterpulsation, there are other factors that influence survival. Before 1978 myocaridal preservation during cardiac surgery in most of our patients was by coronary perfusion or hyperthermic arrest with topical cooling. Since 1979, however, all surgeons in Glasgow have been using moderate hypothermia and hypothermic cardioplegic arrest. $^{1213} \mathrm{~A}$ pulsatile system of cardiopulmonary bypass perfusion has been used in our units for the past three years and this has also influenced results, probably by increasing myocardial blood flow during the free perfusion stage. ${ }^{14}$

Our policy has been to introduce the intra-aortic balloon almost entirely as a means of assisting left ventricular function while preparations are made for surgery or to support patients with reversible left ventricular dysfunction or arrhythmia after surgery. Even patients with major mechanical complications of myocardial infarction will usually have balloon counterpulsation only if they develop cardiogenic shock and do not respond to medical measures.

There are, of course, drawbacks to the more widespread use of intra-aortic balloon pumping. Arterial access may be a considerable problem in elderly patients with tortuous atheromatous arteries and this may completely preclude retrograde access through the femoral artery. A transthoracic route has been advocated to overcome this problem and minimise limb ischaemia. ${ }^{3}$ is This technique requires thoracotomies for insertion and removal of the balloon and carries a potential risk of cerebral embolisation and infection of the mediastinum. Percutaneous insertion of intra-aortic balloons has become much more widely accepted over the last few years; this greatly facilitates the speed and ease of insertion of the balloon catheter but is not free of complications. ${ }^{16-18}$ The economic aspect of balloon pumping will be an important factor if widespread elective use is contemplated in Britain. If the available resources are to be used effectively a conservative policy would be required. These factors are reflected in the small proportion of patients having balloon pumping in our unit.

During the period of study only some patients with postinfarction ventricular septal defect required balloon support. The fact that those who required balloon support all died at operation reflects the severity of myocardial damage in these patients, the overall mortality for this condition in the period of study being $56 \%$. The annual mortality rate for adult open heart surgery in our unit during this period was $6.3 \%$, and the incidence of major complications of intra-aortic balloon pumping was less than the incidence often reported elsewhere; we therefore do not see any necessity to broaden the indication for intra-aortic balloon pumping in our unit. ${ }^{1-616-18}$ Nonetheless, although only $1.5 \%$ of 4090 patients in our series underwent balloon pumping, $27 \%$ of these were long term survivors. This salvage of life was obtained despite our conservative policy for using balloon pumping and without increased operative or hospital mortality. 


\section{References}

1 Bregman D. Mechanical support of the failing heart. Curr Probl Surg 1976;8:1-84.

2 Buckley MJ, Leinbach RC, Kastor JA, et al. Haemodynamic evaluation of intra-aortic balloon pumping in man. Circulation 1970;41,suppl 2:130-4.

3 Macoviak J, Stephenson LW, Edmunds LH, Harken A, MacVaugh H III. Intra-aortic balloon pump: An analysis of five years' experience. Ann Thorac Surg 1980;29:451-8.

4 McEnanay MT, Kay HR, Buckley MJ, et al. Clinical experience with intra-aortic balloon pump support in 728 patients. Circulation 1978;58,suppl 1:124-32.

5 Bolooki H, Williams W, Thurer RJ, et al. Clinical and haemodynamic criteria for use of the intra-aortic balloon pump in patients requiring cardiac surgery. $J$ Thoracic Cardiovasc Surg 1976;72:756-68.

6 Tobias MA, Challen PD, Franklin CB, Phillips G, Varley EM. Intra-aortic balloon counterpulsation. Anaesthesia 1970;34:844-54.

7 Golding LAR, Loop FD, Peter M, Cosgrove DM, Taylor PC, Phillips DF. Late survival following use of IABP in revascularisation operations. Ann Thorac Surg 1980;30:48-51.

8 Williams DO, Korr KS, Gewirtz H, Most AS. The effect of intra-aortic balloon counter-pulsation on regional myocardial blood flow and oxygen consumption in the presence of coronary artery stenosis in patients with unstable angina. Circulation 1982;66:593-7.

9 Fuhrman TM, Sturm JT, Holuh DA, et al. Right and left ventricular haemodynamic indices as predictors of the need for and outcome of post cardiotomy mechani- cal (intra-aortic balloon pump) support. Trans Am Soc Artif Intern Organs 1979;25:171-5.

10 Felix WR Jr, Barsamian E, Silverman AB. Longterm followup of limbs after use of intra-aortic balloon counterpulsation device. Surgery 1982;91:183-7.

11 Igo SR, Hibbs CW, Trono R, et al. Intra-aortic balloon pumping. Theory and practice. Experience with 325 patients. Artif Organs 1978;2:249-56.

12 Flaherty JT, Schaffy HV, Goldman RA, Gott VL. Metabolic and functional effects of progressive degrees of hypothermia during global ischaemia. Am J Physiol 1979;236: H839.

13 Hearse DJ, Braimbridge MV, Jynge P. Cardioplegia. In: Hearse DJ, ed. Protection of the ischaemic myocardium. New York: Raven Press, 1981:151-75.

14 Taylor KM, Wright GS, Reid JM, et al. Comparative studies of pulsatile and non-pulsatile flow during cardiopulmonary bypass. J Thorac Cardiovasc Surg 1978; 75:569-84.

15 Krane AH Jr, Bigelow JC, Page VS. Transthoracic intra-aortic balloon cannulation to avoid repeat sternotomy or removal. Ann Thorac Surg 1976;21:562.

16 Shanian DM, Neptune WB, Ellis $H$ jun, Mags PR. Intra-aortic balloon pump morbidity. A comparative analysis of risk factors between percutaneous and surgical techniques. Ann Thorac Surg 1983;36:644-53.

17 Martin RS, Moncure AC, Buckley MJ, Gerald Austen W, Akins C, Leinback RC. Complications of percutaneous intra-aortic balloon insertion. J Thorac Cardiovasc Surg 1983;85: 186-90.

18 Glen Pennington D, Marc Swartz BA, Codd JE, Merjavy JP, Kaiser GC. Intra-aortic balloon pumping in cardiac-surgical patients: $A$ nine year experience. Ann Thorac Surg 1983;36:125-31. 